\title{
Método para preservação da viabilidade e atividade antagônica de trichoderma stromaticum, agente de biocontrole da vassoura-de-bruxa do cacaueiro
}

\author{
Cleber Novais Bastos
}

CEPLAC/SUPOR/ERJOH, CP 46, CEP 67105-970 Marituba, PA.

Autor para correspondência: Cléber Novais Bastos. e-mail: clebernbastos@ hotmail.com

Data de chegada: 27/03/2007. Aceito para publicação em: 10/01/2008

\section{RESUMO}

Bastos, C. N. Método para preservação da viabilidade e atividade antagônica de Trichoderma stromaticum, agente de biocontrole da vassourade-bruxa do cacaueiro. Summa Phytopathologica, v.34, n.3, p.265-266, 2008

Avaliou-se a viabilidade da massa esporógena de Trichoderma stromaticum, através do crescimento micelial em meio de cultivo e a atividade antagônica (parasitária) em vassouras secas de cacaueiro, após a preservação de quatro isolados (Ts1606, Ts3107, Ts0108, Ts2705) do antagonista por quatro anos em fragmentos de vassoura secas, acondicionados em tubos de ensaio e mantidos em refrigerador com temperatura aproximada de $5{ }^{\circ} \mathrm{C}$. Todos os isolados preservados apresentaram-se viáveis, com crescimento e esporulação normais e continuavam antagônicos a Crinipellis perniciosa. Os resultados obtidos indicam a eficiência do método, que é capaz de manter os isolados de T. stromaticum viáveis por longos períodos de tempo, preservando características morfológicas, fisiológicas e antagônicas.

Palavras chave adicionais: antagonista, controle biológico, cacaueiro, Tricovab.

\section{ABSTRACT}

Bastos, C. N. Method for preservation of viability and antagonic activity of Trichoderma stromaticum, biocontrol agent of witches'broom disease of cocoa. Summa Phytopathologica, v.34, n.3, p.265-266, 2008

After four years of preservation by using dried cocoa brooms in fridge at $5{ }^{\circ} \mathrm{C}$, the viability of four isolates (Ts1606, Ts3107, Ts0108, Ts2705) of Trichoderma stromaticum was evaluated based on germination of conidia, mycelium growth in a culture medium and antagonistic activity on dry cocoa brooms. All the isolates preserved maintained viability, showing normal growth, sporulation and antagonistic activity against Crinipellis perniciosa.. These results indicate the efficience of the method for the long term preservation of $T$. stromaticum, maintaining their morphological, physiological, and antagonistic characteristics.

Additional keywords: antagonist, biological control, cocoa tree, Tricovab.

As repicagens de rotina dos fungos fitopatogênicos e daqueles utilizados no controle biológico de pragas e doenças das plantas provocam mudanças na virulência, nas características das culturas e decréscimo da esporulação. Para impedir ou diminuir essas mudanças adversas e minimizar contaminações, as culturas originais podem ser preservadas por técnicas que reduzem ou paralisam o desenvolvimento do organismo (9).

Vários métodos de preservação têm sido descritos visando manter culturas com suas características originais por longos períodos e livre de contaminações $(6,9)$. Capacidade de esporulação e patogenicidade são as características mais importantes para os micólogos e fitopatologistas (1). Os métodos mais utilizados nos laboratórios de micologia e fitopatologia são as repicagens periódicas, água destilada (Castellani) e liofilização. A preservação de fitopatógenos em tecidos secos do hospedeiro é uma técnica interessante na qual o organismo pode ser mantido íntegro durante um ano ou mais (7).

Trichoderma stromaticum Samuels \& Pardo-Schultheiss (8) é um micoparasita do fungo Crinipellis perniciosa (Stahel) Singer, causador da vassoura-de-bruxa do cacaueiro. Atualmente o fungo é produzido em alta escala pela Unidade de Biocontrole do CEPEC na CEPLAC, em Itabuna, BA, na formulação do produto comercial conhecido como Tricovab (5). A aplicação do produto é recomendada pela CEPLAC como parte do manejo integrado da vassoura-de-bruxa. No entanto, ensaios realizados anteriormente com vassouras colonizadas por $T$. stromaticum, mantidas em freezer $\left(-20^{\circ} \mathrm{C}\right)$ e em temperatura ambiente de laboratório $\left(26 \pm 2{ }^{\circ} \mathrm{C}\right)$ revelaram que o fungo perde a viabilidade após poucos meses de preservação (resultados não publicados).

Este trabalho teve por objetivo avaliar o método de preservação do antagonista T. stromaticum em vassoura seca de cacaueiro, levandose em conta a manutenção da viabilidade e capacidade parasitária ou antagônica das culturas.

Foram selecionados quatro isolados de T. stromaticum (Ts1606, Ts3107, Ts2705 e Ts0108), obtidos a partir de vassouras secas de cacaueiros, naturalmente colonizadas pelos isolados do antagonista. Pedaços de vassouras (10 a $15 \mathrm{~cm}$ de comprimento) colonizadas com propágulos do antagonista foram acondicionados em tubos de ensaios com tampas rosqueadas, sendo, posteriormente, os tubos mantidos no refrigerador com temperatura aproximada de $5^{\circ} \mathrm{C}$, por um período de quatro anos. Quando do início da preservação, os isolados fúngicos mostravam-se viáveis e esporulantes in vitro. Após esse período de 
preservação, os tubos de ensaio foram abertos, os tecidos colonizados retirados e sob microscópio estereoscópico com auxílio de um estilete esterilizado realizou-se a transferência direta de massas esporógenas do antagonista para tubos de ensaio contendo meio de batata-dextroseágar (BDA), que foram, posteriormente, incubados a $25 \pm 2{ }^{\circ} \mathrm{C}$, na ausência de luz. Após o desenvolvimento das colônias, cada isolado foi repicado para placas de Petri contendo meio de batata-caldo-decana-ágar (BCCA), as quais foram mantidas à temperatura ambiente do laboratório.

Para o teste de antagonismo em vassouras secas, os isolados foram cultivados em meio de batata-caldo-de-cana (BCC) como descrito por Bastos (3). Os testes foram realizados em vassouras secas de cacaueiros penduradas no interior de gabinetes (câmara indutora de basidiomas) a $26 \pm 2{ }^{\circ} \mathrm{C}$, sob fotoperíodo de $12 \mathrm{~h}$. As vassouras, em número de 25 para cada isolado, foram pulverizadas com suspensões de esporos $\left(1,6 \times 10^{7}\right.$ esporos $\left./ \mathrm{ml}\right)$ dos isolados até o ponto de escorrimento. Para induzir a colonização das vassouras pelos isolados do antagonista e, também, induzir a produção de basidiomas de C. perniciosa, as vassouras foram aspergidas com água diariamente por um período de $8 \mathrm{~h}$.

Todos os isolados de $T$. stromaticum preservados apresentaram desenvolvimento micelial quando retirados das vassouras e repicados para os tubos com BDA. Quanto ao crescimento micelial em meio de BCCA em placas de Petri, todos os isolados, mesmo após o longo período de preservação apresentaram excelente crescimento e esporulação, após oito dias de incubação. No tocante a esporulação em meio líquido de BCC para produção de inóculo, observou-se que os isolados não apresentaram mudanças em relação aos resultados obtidos antes da preservação. Aparecido et al., (1) mencionaram que um método de preservação deve manter as características originais dos patógenos como a capacidade de esporulação e patogenicidade. Além disso, o método deve ter baixo custo e requerer pouco espaço, requisitos preenchidos pelo método avaliado neste trabalho.

Para o fator antagonismo, observou-se que oito dias após a aplicação todos os isolados colonizaram as vassouras, formando na superfície das mesmas massas esporógenas brancas semelhantes àquelas observadas nas culturas de origem, mantidas por repicagens periódicas (2). Foi verificado que nas vassouras parasitadas não ocorreu formação de basidiomas de $C$. perniciosa, enquanto que, nas vassouras não tratadas (testemunha) a esporulação do patógeno foi normal (basidiomas não contabilizados). Esses resultados corroboram com aqueles obtidos por Bastos (2), quanto à ação de T. stromaticum na paralisação e supressão na produção de basidiomas. Isto é atribuído a mecanismos de competição por nutrientes, parasitismo e espaço na superfície das vassouras parasitadas $(2,3,4)$.

Os resultados indicam a capacidade de sobrevivência de $T$. stromaticum após preservação em vassouras secas de cacaueiros a 5 ${ }^{\circ} \mathrm{C}$, uma vez que os isolados mostraram-se viáveis após quatro anos de preservação, exibindo características de crescimento micelial, esporulação e atividade antagônica normais.

\section{AGRADECIMENTOS}

O autor agradece ao Dr. Antônio de Carlos Barros Mendes (Ceplac/ Supor) pela revisão crítica do texto.

\section{REFERÊNCIAS BIBLIOGRÁFICAS}

1. Aparecido, C. C.; Egydio A. P. M.; Figueiredo, M. B. Avaliação de três métodos para preservação de fungos fitopatogêncicos. Summa Phytopathologica, Botucatu, v.27, n. 4, p.421-424, 2001.

2. Bastos, C. N. Resultados preliminares sobre a eficácia de Trichoderma viride no controle da vassoura-de-bruxa (Crinipellis perniciosa) do cacaueiro. Fitopatologia Brasileira, Brasília, v.13, n.4, p.340-342, 1988.

3. Bastos, C. N. Mycoparasitic nature of the antagonism between Trichoderma viride and Crinipellis perniciosa. Fitopatologia Brasileira, Brasília, v.21, n 1, p. 40-54, 1996a.

4. Bastos, C. N. Potencial de Trichoderma viride no controle da vassoura-de-bruxa (Crinipellis perniciosa) do cacaueiro. Fitopatologia Brasileira, Brasília, v.21, n.4, p.509-512, 1996 b.

5. Bezerra, J. L.; Costa, J. C. B.; Pomela, A. W. V.; Almeida, O. C. Como produzir tricovab para controlar a vassoura-de-bruxa do cacaueiro. Fitopatologia Brasileira, Brasília, v.25, Supl.,p.359, 2000 .

6. Figueiredo, M. B.; Pimentel, C. P. V. Métodos utilizados para conservação de fungos na Micoteca da Seção de Micologia Fitopatológica do Instituto Biológico. Summa Phytopathologica, Piracicaba, v.1, n. 4 p.299-302, 1975.

7. Pimentel, C. P. V.; Pitta, G. B. P. ; Figueiredo, M. B. Preservação da patogenicidade de alguns fungos conservados em água destilada. O Biológico, São Paulo, v.46, n.12, p.279-308, 1980.

8. Samuels, G. J.; Pardo-Shultheiss, R.; Hebbar, K. P.; Lumsden, R. D.; Bastos, C. N.; Costa, J. C. B.; Bezerra, J. L. Trichoderma stromaticum sp. nov. a parasitic of the cacao witches'broom pathogen. Mycological Research, London, v.104, n.6, p.760764, 2000 .

9. Smith, D.; Waller, J. M. Culture collections of microorganisms: their importance in tropical plant pathology. Fitopatologia Brasileira, Brasília, v.17, n.1, p.5-12, 1992. 